\title{
Knowledge and Practices Related to Unused Medications in Households in Serbia
}

\author{
Zorica Terzic-Supic ${ }^{1}$, Dragica Bukumiric ${ }^{2}$, Milena Santric-Milicevic ${ }^{1}$, Aleksandar Corac ${ }^{3}$, \\ Milica Paut Kusturica ${ }^{4}$, Momcilo Mirkovic ${ }^{3}$, Zoran Bukumiric ${ }^{5}$, Jovana Todorovic ${ }^{1, *}$, Biljana Ristic ${ }^{5}$, \\ Goran Trajkovic 5
}

${ }^{1}$ Institute of Social Medicine, School of Medicine, University of Belgrade, Dr Subotica 15, Belgrade, SERBIA.

${ }^{2}$ Department of Planning, Analysing and Statistics, Primary health care centre, Miloša Obrenovica 2-4, 26000, Pancevo, SERBIA. ${ }^{3}$ Department for Preventive Medicine, School of Medicine, University of Pristina - Kosovska Mitrovica, Anri Dinan bb, 38220 Kosovska Mitrovica, SERBIA.

${ }^{4}$ Department of Pharmacology, Toxicology and Clinical Pharmacology, School of Medicine, Hajduk Veljkova 3, 21000 Novi Sad, SERBIA.

${ }^{5}$ Institute of Medical Statistics and Informatics, School of Medicine, University of Belgrade, Dr Subotica 15, 11000 Belgrade, SERBIA.

\begin{abstract}
Background: The objective of this study was to examine the knowledge and practices regarding expired medications and to identify their potential predictors. Methods: A cross-sectional study was conducted, between August and November of 2014 in Regional Community Primary Health Care centre in Serbia on 609 patients. The research instrument was the questionnaire. Univariate and multivariate logistic regression analyses were applied. Results: The lack of knowledge about the treatment of expired medications had $67.5 \%$ respondents, while $87.3 \%$ of the respondents had inappropriate practice. In the model of multivariate logistic regression with lack of knowledge as dependent variable, statistically significant predictors were: unemployment $(\mathrm{OR}=2.21 ; 95 \% \mathrm{Cl}$ : 1.35-3.59), lower economic status (OR $=1.67 ; 95 \% \mathrm{Cl}: 1.01-2.58)$, unread instructions for use $(\mathrm{OR}=3.26 ; 95 \% \mathrm{Cl}: 1.51-7.02)$, unchecked medications' expiration date (OR $=3.30 ; 95 \% \mathrm{Cl}: 1.22-8.92$ ). In the second model of multivariate logistic regression with inappropriate practice as dependant variable, statistically significant predictors were: the lower education level $(\mathrm{OR}=1.75 ; 95 \% \mathrm{Cl}$ : $1.09-2.80)$, unemployment $(\mathrm{OR}=2.66$; $95 \% \mathrm{Cl}: 1.17-6.05)$, families with members incapable of taking care of their medicines independently $(\mathrm{OR}=0.27 ; 95 \% \mathrm{Cl}: 0.12-0.61)$ and lack of knowledge $(\mathrm{OR}=4.09 ; 95 \%$ $\mathrm{Cl}$ : 2.31-7.23). Conclusion: Our study shows that there is a need for stronger control of the implementation of legally defined procedures for disposal of medications, as well as a proactive education of population about proper disposal of medications.
\end{abstract}

Key words: Knowledge, Practice, Disposal of medications, Expired medications, inappropriate practice

\section{INTRODUCTION}

Storing the expired medications in homes is nothing unusual. ${ }^{1,2}$ The quantity of such medications is approximately $0.28 \mathrm{~kg}$ per person. ${ }^{3}$ There are two main reasons why people store the medications at their homes. One of them is self-medication ${ }^{4}$ and the other is involuntary hoarding of medications, which often leads to the storage of medications after the expiration period. Self-medication can be seriously harmful and even fatal as it has potential to delay visits to the health professionals. ${ }^{4,5}$ On the other hand, involuntary hoarding of medications is practical storage of them, as the person look for the appropriate place for disposal, required by the law. ${ }^{6}$

Storing of non-used medications increases the risk of wide spectrum of possible problems: misuse, ${ }^{7}$ adverse drug reactions, overdose or accidental poisoning., ${ }^{2,5}$ Additionally, signifi-
Submission Date: 24-10-2018 Revision Date: 23-11-2018; Accepted Date: 18-01-2019

DOI: 10.5530/ijper.53.2.43 Correspondence:

Dr. Jovana Todorovic, Institute of Social Medicine, School of Medicine, University of Belgrade, Dr Subotica 15, 11000 Belgrade, SERBIA. Phone: +381 112643830 , Fax: +381112659533

E-mail: jovana.todorovic@ mfub.bg.ac.rs

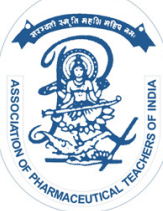

www.ijper.org 
cant number of patients discard these medications into environment, which has a negative consequences for both environment and people's health. ${ }^{9,10}$

Some researchers showed that the medications stored in homes are kept in inadequate places, ${ }^{11}$ and unused medications are inappropriately disposed. ${ }^{12}$ Liquid medications are often rinsed down the sink, as opposed to solid tablets and capsules which are thrown into the trash bin. ${ }^{13}$

The studies of knowledge, attitudes and practices regarding the proper storage and disposal of unused medications are not common. ${ }^{14}$ There is confusion about "proper" way for disposal of expired medications, as many countries have not defined standards and protocols for it. The situation becomes complicated if pharmacies refuse or do not support undertaking of unused medications ${ }^{12,15}$ or they apply unacceptable practices, like spilling it into the sink. ${ }^{16}$

As of 2008, Serbia has several regulations and recommendations providing a good basis for the appropriate waste management. According to the Law for the Waste Control, 2010 and the national guidelines for safe control of the medical waste, medical waste includes the municipal waste from the patients' households and pharmaceutical waste. ${ }^{17}$ These are complemented by Regulations for managing the medical waste ${ }^{18}$ and by recommendations ${ }^{19}$ which arise from the project "Technical support for the treatment of medical waste in Serbia". Pharmacies, state or private, established as health institutions are obliged to accept pharmaceutical waste and unused medications and to provide containers for that purpose, free of charge and for all citizens. ${ }^{18}$ This regulation is defined in a way that there is a space for different interpretations. For example, the existence of containers in clearly defined areas in pharmacy is defined, but it is unclear whether it is available for citizens or for the employees only. This creates confusion even for the informed citizens and disables the further spread of knowledge on what practices are appropriate relating the disposal of unused medications.

Before this research, there was only one study on this subject, conducted in Serbia, in the South Backa District. Its objectives were to investigate the storage and disposal practices for medications and differences in medications' disposal behaviour between the urban and rural population. ${ }^{20}$ This research showed that almost $90 \%$ of participants disposed their expired medications into the trash or into the toilet, although most of them agreed that this practice is detrimental to the environment.

\section{Research objective}

In spite of the existing legislative frame, although with insufficient implementation, practices regarding medications that are expired remain unclear, so the objective of this study was to examine the knowledge and practices regarding expired medications and to identify factors associated with it.

\section{MATERIALS AND METHODS}

Research was designed as the cross-sectional study of knowledge and practices of patients in the outpatient care. It was conducted in 59 general practitioners (GP) offices at the Regional Community Primary Healthcare Centre Pancevo in the period from August to November 2014. Out of 671 patients who visited their chosen GP on a day of research, 46 did not give their consent to participate and 16 did not meet the criteria for the participation in research. Criteria for inclusion in the study were the following: adult patients (18 years and older), good general health condition based on physician's assessment and ability to understand and self-administer the questionnaire. The total number of respondents included in research was 609 .

\section{The research instrument}

The research instrument was the questionnaire created on the basis of questionnaires used in similar researches. ${ }^{16,21}$ The questionnaire consisted of 58 questions divided into two sections. The first section, with 10 questions, referred to socio-demographic and socio-economic characteristics: gender, age, marital status, years of education, employment status (employed, unemployed, retired), residence (urban, rural) and the self-rated economic status of the family (good, average or poor). This section also included questions on family characteristics: number of family members, having children younger than seven years ('Do you have children under the age of 7 living in your household?', Yes/No), individuals who were not capable to take care of their therapy independently ('Do you have family member who is not capable of taking care of his/ her therapy independently?', Yes/No). Based on the reported number of family members, the variable 'number of family members was transformed into binary variable: living alone vs. living with family.

The second section, with 48 questions, referred to the existence of chronic or acute diseases (Yes/No), the way and the place the medications are being kept in home ('How do you store your medications' plastic bag/ 
paper bag/drawer/ other; 'Where do you store your medications?', hallway/ living room/ kitchen/ bathroom/ bedroom/ other), the presence of expired medications in home ('Do you have medications which you do not use?', Yes/No), reading the instructions for use ('Do you read the instructions for use of medications?', Yes/No), checking the expiration date ('Do you check expiration date on the medications?', Yes/No), the way medications was obtained ('Who prescribed you the medication?', Doctor/ pharmacist/ I bought it/ other), the reasons for storing medications, knowledge and practices with expired medications. Knowledge about expired medications was assessed with questions:

1. Are you familiar with the effects of medications after the expiration date? a) The effect is the same as before; b) They have less effect or no effect at all after the expiration date; c) Their effect is harmful or it may be toxic after the expiration date; d) I do not know;

2. According to your opinion the best place for the collection of expired medications is: a) The special box for drugs collection e.g. container in the pharmacy, b) Special box for drugs collection e.g. container in healthcare centre, c) Special box for drug collection e.g. container in public place, d) Something else;

3. Can the medications which you threw out, rinsed down the sink or burned, be harmful for environment? a) Yes, b) I do not know, c) No.

Practices about expired medications were assessed with questions:

1. What do you do with the medications in solid form (e.g. tablets, capsules, etc) which are expired? a) Throw them out in the trash, b) Flush them down the toilette or rinse them down the sink, c) Burn them, d) Keep them in the special place at home, e) Give them back to the pharmacy or to the health centre, f) Others;

2. What do you do with the medications in liquid form (e.g. syrups, drops, etc) that are expired? a) Throw them out in the trash, b) Flush them down the toilette or rinse them down a sink, c) Burn them, d) Keep them in a special place at home, e) Bring them back to the pharmacy or to the healthcare centre, $\mathrm{f}$ ) Others;

3. What do you do with medications in semisolid form (e.g. cream, balms, etc) that have been expired: a) Throw them out in the trash, b) Flush them down the toilette or rinse them down the sink, c) Burn them, d) Keep them in the special place at home, e) Bring them back to the pharmacy or to the health- care centre, f) Others. The correct answer to these three questions was the one under (e).

Pre-testing of questionnaire was conducted on 10 respondents, to assure that questions are understandable and logic, that completing the questionnaire takes $20 \mathrm{~min}$ on average. Test - retest was conducted two weeks after and kappa coefficient as the measure of agreement between items was 0.8 or higher.

\section{Ethic approval}

The Ethics Committee of the Primary Healthcare Centre Pancevo gave its approval for conducting the research, in accordance to the Article 33 of Healthcare Centre Statute. Respondents were informed about the protection of privacy and the possibility to recede at any time. Confidentiality and anonymity of the data were guaranteed. The verbal consent was obtained from respondents.

\section{Variables included in research}

The data analysis included: variables relating to sociodemographic, socio-economic and family characteristics of the respondents (age, sex, marital status, years of education, employment status and place of residence, living alone or with family, having children under the age of 7 , having family member incapable of taking care of their own medicines), variables relating to the use of medications for chronic and acute diseases, storage of medications which are not used (the term "medications that are not used" refers to the possession of unused medications or to the expired ones) and reading the instructions for the use and checking the expiration date of medications. Finally, the 2 dependent variables were related to lack of knowledge and inappropriate practices. Dependent variable the lack of knowledge was obtained on the basis of wrong answers to any of the questions relating to the assessment of knowledge about expired medications (effects of medications after the expiration date, best place for the collection of expired medications, effects on the environment). Dependent variable-inappropriate practices, was obtained on the basis of answers to any question regarding the practices about expired medications (practices of disposal of medications in solid, liquid or semisolid form).

\section{Statistical analysis}

Data analysis was done with methods of descriptive and analytical statistics. Association between the dependent variables and potential predictors was analysed by univariate logistic regression models. Independent variables which were significant in univariate models of logistic regression were used as the inde- 
pendent variables in the multivariate logistic regression models. The variable, the lack of knowledge was used as predictor, in the regression model of inadequate practice. Statistical data analysis was performed using IBM SPSS Statistics 22 (SPSS Inc., Chicago, IL, USA)

\section{RESULTS}

Socio-demographic characteristics of 609 respondents are shown in Table 1.

Medications for chronic diseases were used by 346 (56.8\%) and for acute diseases by 201 (33.0\%) respondents. Unused medications were in possession of 381 $(65.6 \%)$ respondents. The instructions for use were read by $509(84.4 \%)$ and the expiration date was checked by $541(89.6 \%)$ respondents. Participants mainly have one place to keep their medications in the house $(69 \%)$ and in a closed space $(69.9 \%)$. Medications were stored in a box $(49.0 \%)$ or a drawer $(35.3 \%)$, in the living room (35.6\%), bedroom $(24.3 \%)$ or kitchen $(21.4 \%)$. This sort of a household pharmacy was not locked in $94.8 \%$ of the cases and it was easily accessible to children $(24.6 \%)$ or to the individuals who were not capable of taking care of their medications independently $(31.0 \%)$.

\begin{tabular}{|c|c|}
\hline Term & n (\%) \\
\hline Age (years) $x \pm S D$ & $52.3 \pm 16.0$ \\
\hline $\begin{array}{l}\text { Gender } \\
\text { Male } \\
\text { Female }\end{array}$ & $\begin{array}{l}245(40.2 \%) \\
364(59.8 \%)\end{array}$ \\
\hline $\begin{array}{c}\text { Marital status } \\
\text { Single } \\
\text { Married }\end{array}$ & $\begin{array}{l}201(33.1 \%) \\
407(66.9 \%)\end{array}$ \\
\hline $\begin{array}{l}\text { Years of education } \\
>12 \text { years } \\
8-12 \text { years } \\
8 y r \text { or less }\end{array}$ & $\begin{array}{l}137(22.5 \%) \\
347(57.1 \%) \\
124(20.4 \%)\end{array}$ \\
\hline $\begin{array}{l}\text { Employment status } \\
\text { Employed } \\
\text { Unemployed } \\
\text { Retired }\end{array}$ & $\begin{array}{l}223(36.7 \%) \\
177(19.1 \%) \\
208(34.2 \%)\end{array}$ \\
\hline $\begin{array}{l}\text { Residence } \\
\text { Rural } \\
\text { Urban }\end{array}$ & $\begin{array}{l}376(61.7 \%) \\
233(38.3 \%)\end{array}$ \\
\hline Living alone & $53(8.7 \%)$ \\
\hline Children under 7 years & $126(20.7 \%)$ \\
\hline $\begin{array}{l}\text { Persons incapable of taking care of their } \\
\text { medications independently }\end{array}$ & $56(9.2 \%)$ \\
\hline $\begin{array}{c}\text { Self-rated economic status } \\
\text { Good } \\
\text { Average } \\
\text { Poor }\end{array}$ & $\begin{array}{c}13(2.1 \%) \\
444(73.3 \%) \\
149(24.6 \%)\end{array}$ \\
\hline
\end{tabular}

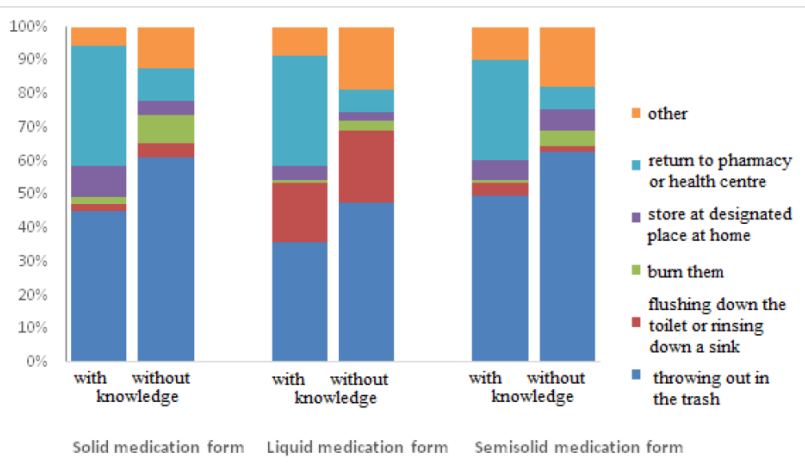

Figure 1: The frequency of behaviour related to knowledge towards medications with expired date.

Medications were in 296 cases (48.6\%) supplied upon the doctor's advice/receipt, but 98 respondents (16.1\%) got them on their own initiative. Reasons for keeping the unused medications were: leftover from the previous treatment $(40.9 \%)$, accumulation for the future use (28.0\%), expired medications $(11.9 \%)$, use by other family members $(16.6 \%)$ and other reasons $(2.6 \%)$. Lack of knowledge about the treatment of expired medications had $390(67.5 \%)$ respondents, while inappropriate practice had $500(87.3 \%)$ respondents. Inappropriate practice with expired medications had $73.9 \%$ participants with knowledge and $94.0 \%$ without it, which was statistically significant difference $(p<0.001)$.

Expired medications were most frequently thrown out in the trash $(52.2 \%)$ while $16.2 \%$ was brought back to the pharmacy. Respondents with adequate knowledge less frequently threw the medications out in the trash versus respondents with lack of it: medications in solid form $(45.1 \%$ vs $61.1 \%$, respectively), in liquid form (35.8\% vs $47.8 \%$, respectively) and in semisolid form (50.0\% vs $62.7 \%$, respectively). Participants with adequate knowledge more often bring back the medications to the pharmacy compared with the ones with lack of it: medications in solid form $(35.7 \%$ vs $9.5 \%)$, in liquid form $(33.0 \%$ vs $7.0 \%)$ and in semisolid form $(30.1 \%$ vs $6 \%)$. There is statistically significant difference in frequency of disposal practice of solid $(p<0.001)$, liquid $(p<0.001)$ and semisolid $(p<0.001)$ forms of expired medications between the respondents with and without the adequate knowledge. Figure 1 shows the frequent practice relating to the knowledge about expired medications.

Univariate and multivariate logistic regression with lack of knowledge about the treatment of expired medications as dependent variable are shown in Table 2. In univariate logistic models, 6 out of 15 variables relating to the socio-demographic characteristics of the respondents, the presence of acute or chronic disease and the practice regarding the medications (possession of the 
unused medications, introduction with the instructions for the use, checking the expiration date), were statistically significant.

In the model of multivariate logistic regression (Table 2) with lack of knowledge about practices with the expired medications as dependent variable, statistically significant predictors were: unemployment (OR $=2.21 ; \mathrm{CI} 95 \%$ 1.35-3.59), lower economic status ( $\mathrm{OR}=1.67$; $\mathrm{CI} 95 \%$ 1.01-2.58), not reading the instructions for use $(\mathrm{OR}=3.26$; CI95\% 1.51-7.02) and not checking the expiration date $(\mathrm{OR}=3.30$; $\mathrm{CI} 95 \%$ 1.22-8.92). There was no significant collinearity among predictors.

Table 3 shows the univariate and multivariate logistic regression of inappropriate practices with expired medicines as dependent variable. In multivariate logistic regression model (Table 3) with inappropriate practice as dependent variable the statistically significant predictors were: the lower educational level $(\mathrm{OR}=1.75$; $\mathrm{CI} 95 \%$ 1.09-2.80), unemployment ( $\mathrm{OR}=2.66$; $\mathrm{CI} 95 \% 1.17$ 6.05), families whose members were not capable to take care of their medications independently $(\mathrm{OR}=0.27$; CI95\% 0.12-0.61) and lack of knowledge (OR=4.09; CI95\% 2.31-7.23). There was no significant collinearity among predictors.

\section{DISCUSSION}

Study examines the knowledge and practices regarding disposal of expired medications and the possible predictors of knowledge and practices in a sample of 609 respondents in Health Centre Pancevo. Pancevo was chosen because of the fact that it is marked on domestic and foreign maps of Environmental Protection as the black point. ${ }^{22}$ Also, this is the first town in Serbia which had the local strategy for public health, developed within the project The Health of community - development and implementation of local strategies for public health. ${ }^{21}$ Now it has the strategic city development plan for the period 2014-2020..$^{23}$

In our study $2 / 3$ of the respondents have medications that are unused, similarly to research in New Zealand, while this percentage in Ireland is higher and is almost $90 \%{ }^{15}$

Also, in our research, the respondents throw out to trash $50 \%$ of unused or expired medications. This practice is similar to practice of some other populations but from 10-20 years ago. In 1996 in Canada, 54\% of unused medications were disposed in trash and 35.4\% were flushed down the toilette or rinsed down a sink. ${ }^{24}$ In six years, Canada succeeded in reducing inappropriate disposal practice, to $50 \%$ of the medications thrown

\begin{tabular}{|c|c|c|c|c|}
\hline \multirow{2}{*}{ Independent variable } & \multicolumn{2}{|c|}{ Univariate model } & \multicolumn{2}{|c|}{ Multivariate model } \\
\hline & OR $(95 \% \mathrm{Cl})$ & p & OR $(95 \% \mathrm{Cl})$ & $p$ \\
\hline Age (years) & $1.00(0.99-1.01)$ & 0.499 & & \\
\hline Sex & $0.73(0.51-1.05)$ & 0.087 & & \\
\hline Marital status & $1.23(0.85-1.77)$ & 0.276 & & \\
\hline Years of education & $1.55(1.18-2.03)$ & 0.001 & $1.11(0.81-1.53)$ & 0.515 \\
\hline $\begin{array}{c}\text { Employment status } \\
\text { employed } \\
\text { unemployed } \\
\text { retired person }\end{array}$ & $\begin{array}{c}\text { ref. category } \\
2.71(1.72-4.28) \\
1.55(1.03-2.33)\end{array}$ & $\begin{array}{c}<0.001 \\
0.034\end{array}$ & $\begin{array}{l}2.21(1.35-3.59) \\
1.28(0.82-2.01)\end{array}$ & $\begin{array}{l}0.001 \\
0.282\end{array}$ \\
\hline Residence & $0.65(0.45-0.92)$ & 0.017 & $0.82(0.55-1.23)$ & 0.340 \\
\hline Living alone & $0.67(0.37-1.26)$ & 0.226 & & \\
\hline Children under 7 years & $0.92(0.60-1.41)$ & 0.720 & & \\
\hline $\begin{array}{l}\text { Person incapable to take care of their medications } \\
\text { independently }\end{array}$ & $0.88(0.49-1.58)$ & 0.661 & & \\
\hline Self-rated economic status & $1.72(1.16-2.54)$ & 0.007 & $1.67(1.01-2.58)$ & 0.019 \\
\hline Using medications for chronic diseases & $1.01(0.77-1.55)$ & 0.628 & & \\
\hline Using medications for acute diseases & $0.99(0.69-1.43)$ & 0.966 & & \\
\hline Possession of unused medications & $0.86(0.59-1.25)$ & 0.431 & & \\
\hline Reading the instructions for use & $5.33(2.62-10.88)$ & $<0.001$ & $3.26(1.51-7.02)$ & 0.003 \\
\hline Checking the expiration date before using the medication & $6.03(2.37-15.32)$ & $<0.001$ & $3.30(1.22-8.92)$ & 0.019 \\
\hline
\end{tabular}




\begin{tabular}{|c|c|c|c|c|}
\hline \multirow{2}{*}{ Independent variable } & \multicolumn{2}{|c|}{ Univariate model } & \multicolumn{2}{|c|}{ Multivariate model } \\
\hline & OR (95\% CI) & p & OR $(95 \% \mathrm{Cl})$ & $p$ \\
\hline Age (years) & $1.01(0.99-1.03)$ & 0.158 & & \\
\hline Sex & $1.32(0.80-2.15)$ & 0.282 & & \\
\hline Marital status & $1.06(0.63-1.80)$ & 0.821 & & \\
\hline Years of education & $2.19(1.47-3.26)$ & $<0.001$ & $1.75(1.09-2.80)$ & 0.021 \\
\hline $\begin{array}{l}\text { Employment status } \\
\text { employed } \\
\text { unemployed } \\
\text { retired person }\end{array}$ & $\begin{array}{c}\text { ref. category } \\
3.85(1.87-7.94) \\
2.07(1.18-3.64)\end{array}$ & $\begin{array}{l}<0.002 \\
0.012\end{array}$ & $\begin{array}{l}2.66(1.17-6.05) \\
1.35(0.71-2.58)\end{array}$ & $\begin{array}{l}0.019 \\
0.359\end{array}$ \\
\hline Residence & $0.78(0.48-1.29)$ & 0.340 & & \\
\hline Living alone & $1.07(0.44-2.62)$ & 0.877 & & \\
\hline Children under 7 years & $1.08(0.59-1.98)$ & 0.808 & & \\
\hline $\begin{array}{l}\text { Persons incapable to take care of their medications } \\
\text { independently }\end{array}$ & $0.44(0.22-0.86)$ & 0.016 & $0.27(0.12-0.61)$ & 0.002 \\
\hline Self-rated economic status & $2.07(1.15-3.71)$ & 0.015 & $0.46(0.75-2.84)$ & 0.264 \\
\hline Using medications for chronic diseases & $1.34(0.82-2.20)$ & 0.239 & & \\
\hline Using medications for acute diseases & $1.16(0.68-1.96)$ & 0.580 & & \\
\hline Possessing unused medications & $1.06(0.63-1.78)$ & 0.822 & & \\
\hline Reading instructions for use & $14.09(1.93-102.83)$ & 0.009 & $4.90(0.63-8.24)$ & 0.130 \\
\hline Checking the expiration date before using the medication & $8.20(1.11-60.24)$ & 0.039 & $2.26(0.28-8.09)$ & 0.443 \\
\hline Lack of knowledge & 6.57 (3.24-9.57) & $<0.001$ & 4.09 (2.31-7.23) & $<0.001$ \\
\hline
\end{tabular}

out to trash and 19\% flushed down a toilette or sink. ${ }^{25}$ Further research from 2005, showed that $1 / 4$ of the Canadian households had unused medications and 20\% to $70 \%$ of them throw medications into sewage or trash or even bury them instead of bringing them back to the pharmacy. ${ }^{26}$

The similar situation was in: USA, where a half of unused medications were thrown into sewage and $22.9 \%$ were brought back to the pharmacy, ${ }^{27}$ in Kuwait, where $87.7 \%$ of respondents threw the medications to trash or spill them into the water, ${ }^{28}$ United Kingdom and New Zealand. ${ }^{7,12,15}$ On the contrary, Sweden has long tradition of returning the unused medications to pharmacies which dates back to 1971, while the European Union carried out a directive in 2004 that all member states have to ensure the appropriate collection systems for medications that are unused or expired. ${ }^{29}$ In 2001 in Sweden 41\% of respondents returned unused medications to the pharmacies and 7\% threw them out in the trash. In recent research, the percentage of medications thrown out to trash is reduced $(3 \%)$, while the percentage of the medications returned to the pharmacies increased $(43 \%) .{ }^{14}$

Lack of knowledge in our study was associated with: employment status and self-rated economic status, reading the instructions for use and checking the expiration date. Unemployed respondents had 2.21 times greater odds for the lack of knowledge regarding disposal of expired medications comparing to the employed. The respondents who did not read the instructions for use and those who did not check the expiration date had more than three times greater odds for lack of knowledge regarding disposal of expired medications.

In our research, the most important predictor of improper disposal of expired medications was the lack of knowledge. Respondents with lack of knowledge had four times greater odds for inappropriate practices. In other studies, predictor for inappropriate disposal of unused medications was the presence of children under seven years in the family, ${ }^{30-33}$ which was not a significant predictor in our study. In our research, the important predictor was the family members who were not capable of taking care of their medications independently. These families had 2/3 less likelihood for inappropriate practices, which was, probably, the result of the higher responsibility relating the use of the medications.

Respondents with lack of knowledge, in our study threw out the expired medications more often into trash or rinse them down the sink, than returning them to the pharmacy or to the health centre. Although respondents 
may be aware of the legal regulations about appropriate disposal of unused medications and about the adequate place for their collection they can ignore them ${ }^{34}$ in Sweden, $85 \%$ of respondents knew that unused medications should be returned to the pharmacy and $43 \%$ had done it within last year. ${ }^{14}$ However, in our study $73.9 \%$ of well-informed respondents did not dispose the medications appropriately. Reason for this might be the lack of adequate containers for disposal; though its possession is regulated by the law. ${ }^{19,35}$ Recent studies showed that the possible reason for the lack of information was non-existence of consensus about optimal disposal of unused medications. In the group of the respondents who knew where to dispose medications in the institution for collection or pharmacies, $25-30 \%$ of them respected it in comparison to $5-7 \%$ who had no information about the proper disposal. ${ }^{36}$

Disposal of unused medications is becoming the growing problem for local communities and state administration from the aspect of environmental protection. ${ }^{37}$ Appropriate disposal of expired medications can be conducted by joint action on several levels. On the state level, situation could be improved by providing conditions for implementation of existing legislation (placing containers for collecting the unused medications). The next level belongs to health professionals and proper and rational prescription of medications or education. This should aim to better inform the users of health services, since research have shown that $80 \%$ of respondents have never received any information about proper disposal of unused medications, neither from doctors or the media. ${ }^{27,37}$ On community level, actions should provide the information and raise awareness about the importance of proper disposal of medications through the media, which are of vital importance for informing the public. ${ }^{7,12,14,37}$ Information could also be available to users via posters or pamphlets placed in pharmacies or in health institutions.

Limitations of this study relate to the town specifics so the results cannot be generalized to the whole Serbian population. Also, the possible limitation is the fact that it includes only the users of the primary healthcare service. Contribution of this study relates primarily to identification of predictors of knowledge and practices regarding expired medications and provision of basis for future researches. It also points out the necessity for clear formulations in the regulations for the proper disposal of expired medications and the control its implementation to reduce the harmful effects on health and ecology of the community caused by the medical waste.

\section{CONCLUSION}

Providing the safe disposal of unused medications is of high importance for the public health interest. In our study, the most important predictor of inappropriate practice toward expired medications is the lack of knowledge, contributed by unemployment, the lower economic status and omitting to read the instruction for use and to check expiration date. Inappropriate practices are affected by the lower educational level and inversely by the presence of family member who is not capable of taking care of his/her medicines independently.

\section{ETHICAL APPROVAL}

The Ethics Committee of the Primary Healthcare Centre Pancevo gave its approval for conducting the research, in accordance to the Article 33 of Healthcare Centre Statute.

\section{ACKNOWLEDGEMENT}

This work is supported by Ministry of Education, Science and Technological Development of the Republic of Serbia (Grant No. 41004, Contract No. 175042 (2011-2014), Grant No.175087 and Grant No.175046).

\section{CONFLICT OF INTEREST}

The authors declare no conflict of interest.

\section{ABBREVIATIONS}

GP: General Practitioner; OR: Odds ratio; USA: United States of America.

\section{REFERENCES}

1. Glassmeyer ST, Hinchey EK, Boehme SE, Daughton CG, Ruhoy IS, Conerly O, et al. Disposal practices for unwanted residential medications in the United States. Environ Int. 2009;35(3):566-72.

2. Kheir N, Hajj MEI, Wilbur K, Kaissi R, Yousif A. An exploratory study on medications in Qatar homes. Drug Healthc Patient Saf. 2011;3:99-106.

3. Guirguis K. Medications collected for disposal by outreach pharmacists in Australia. Pharm World Sci. 2010;32(1):52-8.

4. Aljinović-Vucić V, Trkulja V, Lacković Z. Content of home pharmacies and self-medication practices in households of pharmacy and medical students in Zagreb, Croatia: findings in 2001 with a reference to 1977. Croat Med J. 2005;46(1):74-80.

5. Carnwell, Ros, Buchanan, Julian. Effective Practice In Health, Social Care And Criminal Justice: A Partnership Approach. McGraw-Hill International. 2008.

6. Ruhoy IS, Daughton CG. Types and quantities of leftover drugs entering the environment via disposal to sewage--revealed by coroner records. Sci Total Environ. 2007;388(1-3):137-48.

7. Braund R, Peake BM, Shieffelbien L. Disposal practices for unused medications in New Zealand. Environ Int. 2009;35(6):952-5.

8. Sorensen L, Stokes JA, Purdie DM, Woodward M, Roberts MS. Medication management at home: medication risk factor prevalence and interrelationships. J Clin Pharm Ther. 2006;31(5):485-91. 
9. Daughton CG. Pharmaceuticals in the environment: Sources and their management. InComprehensive Analytical Chemistry. 2013;62:37-69.

10. Koshy S. Disposal of unwanted medications: throw, bury, burn or just ignore? Int J Pharm Pract. 2013;21(2):131-4.

11. Asefzadeh S, Nassiri-AsI M. Drugs at home in Qazvin, Iran: Community based participatory research. Eur J Sci Res. 2009;32(1):43-7.

12. Tong AYC, Peake BM, Braund R. Disposal practices for unused medications around the world. Environ Int. 2011;37(1):292-8.

13. Wasserfallen JB, Bourgeois R, Büla C, Yersin B, Buclin T. Composition and cost of drugs stored at home by elderly patients. Ann Pharmacother 2003;37(5):731-7.

14. Persson M, Sabelström E, Gunnarsson B. Handling of unused prescription drugs--knowledge, behaviour and attitude among Swedish people. Environ Int. 2009;35(5):771-4.

15. Vellinga A, Cormican S, Driscoll J, Furey M, O'Sullivan M, Cormican M. Public practice regarding disposal of unused medicines in Ireland. Sci Total Environ. 2014;478:98-102.

16. Tong AYC, Peake BM, Braund R. Disposal practices for unused medications in New Zealand community pharmacies. J Prim Health Care. 2011;3(3):197-203.

17. Safe Management With Medical Waste. National Guidelines for the Safe Medical Waste Management. Ministry of Health Republic of Serbia. 2008.

18. Regulation on The Medical Waste Control. 2010.

19. Recommendations for Control of the Pharmaceutical Waste. 2013.

20. Kusturica MP, Sabo A, Tomic Z, Horvat O, Solak Z. Storage and disposal of unused medications: knowledge, behavior and attitudes among Serbian people. Int J Clin Pharm. 2012;34(4):604-10.

21. Lazić L, Šantrić MM, Terzić Z, Bjegović V. Lokalna strategija javnog zdravlja Južnobanatskog okruga. Zb. Rad. i sažetaka, X međunarodni Kongr. Prev Med Vrnjačka Banja. 2008;9.

22. Jelinčić J, Đurović $S$, editors. Zaštita životne sredine: uslov za održivi razvoj. Beograd: Fond za otvoreno društvo, Centar za primenjene evropske studije. 2009 .

23. The Strategy for Development of Pancevo City. 2007. http://www.pancevo. rs/O_STRATEGIJI_RAZVOJA_GRADA_PANCEVA_2014_2020-327-1-3019
24. Kuspis DA, Krenzelok EP. What happens to expired medications? A survey of community medication disposal. Vet Hum Toxicol. 1996;38(1):48-9.

25. COMPAS. FandDA Environmental Assessment Regulations Project Benchmark Survey. A Report to Health Canada. POR-02-13. Ottawa, Ontario, Canada. 2002.

26. Statistics Canada. Disposal of household special wastes. 2005. http://www. statcan.ca/english/freepub/16-002-XIE/2008001/10539-en.htm.

27. Seehusen DA, Edwards J. Patient practices and beliefs concerning disposal of medications. J Am Board Fam Med. 2006;19(6):542-7.

28. Abahussain EA, Ball DE, Matowe WC. Practice and opinion towards disposal of unused medication in Kuwait. Med Princ Pract. 2006;15(5):352-7.

29. Directive 2004/27/EC of the European Parliament and of the council. 2004.

30. Flores G, Tomany-Korman SC, Olson L. Does disadvantage start at home? Racial and ethnic disparities in health-related early childhood home routines and safety practices. Arch Pediatr Adolesc Med. 2005;159(2):158-65.

31. Hapgood R, Kendrick D, Marsh P. How well do socio-demographic characteristics explain variation in childhood safety practices?. J Public Health Med. 2000;22(3):307-11.

32. Hippisley-Cox J, Groom L, Kendrick D, Coupland C, Webber E, Savelyich B. Cross sectional survey of socioeconomic variations in severity and mechanism of childhood injuries in Trent 1992-7. BMJ. 2002;324(7346):1132.

33. Vaughan E, Anderson C, Agran P, Winn D. Cultural differences in young children's vulnerability to injuries: a risk and protection perspective. Health Psychol. 2004;23(3):289-98.

34. CPGSec.460.300 Return of unused prescription drugs to pharmacy stock 2014 . http://www.fda.gov/ICECl/ComplianceManuals/CompliancePolicyGuidance Manual/ucm074399.htm

35. Law for the Waste Control. 2010.

36. Kotchen M, Kallaos J, Wheeler K, Wong C, Zahller M. Pharmaceuticals in wastewater: behavior, preferences and willingness to pay for a disposal program. J Environ Manage. 2009;90(3):1476-82.

37. Wieczorkiewicz SM, Kassamali Z, Danziger LH. Behind closed doors: medication storage and disposal in the home. Ann Pharmacother. 2013;47(4):482-9. doi:10.1345/aph.1R706.

\section{PICTORIAL ABSTRACT}

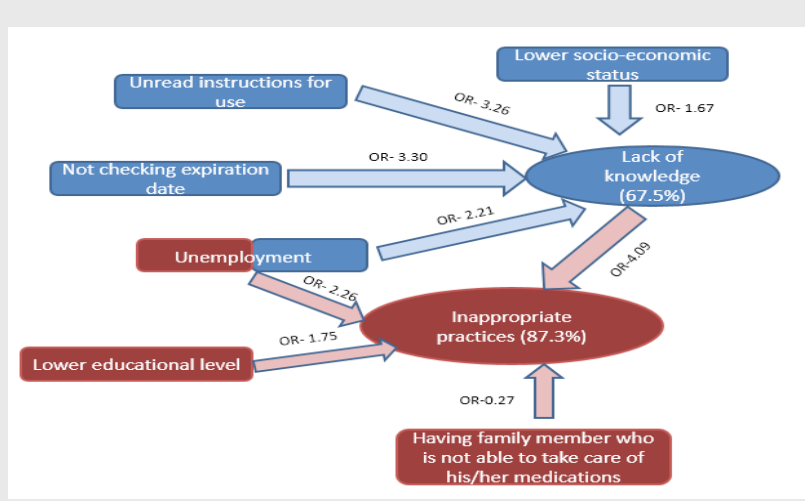

\section{SUMMARY}

- Inappropriate disposal of medications is a public health issue, especially in low and middle income countries. Our study provides information on its association with lack of knowledge, lower educational level and unemployment. The lack of knowledge on proper disposal should be addressed through public health campaigns.

\section{ABOUT AUTHORS}
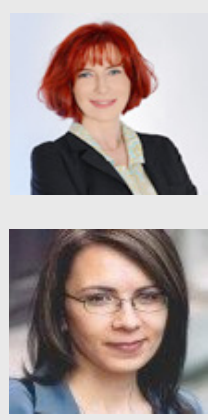

Zorica Terzic-Supic, Graduated at Medical Faculty, University of Belgrade, where she defended her MSc thesis and later PhD. Specialist of Social Medicine. She is working as a professor of Social Medicine, Medical Faculty and Center School of Public Health and Health Management, University of Belgrade. She is engaged in education of undergraduate and postgraduate students in the fields of Social Medicine, Public Health, and Health Management.

Dragica Bukumiric, she is graduated at the Faculty of Medicine. She works as Specialist of Social Medicine in the Primary Healthcare Center Pancevo, she is appointed as vice director. PhD student at the Medical Faculty of Pristina, Kosovska Mitrovica. 

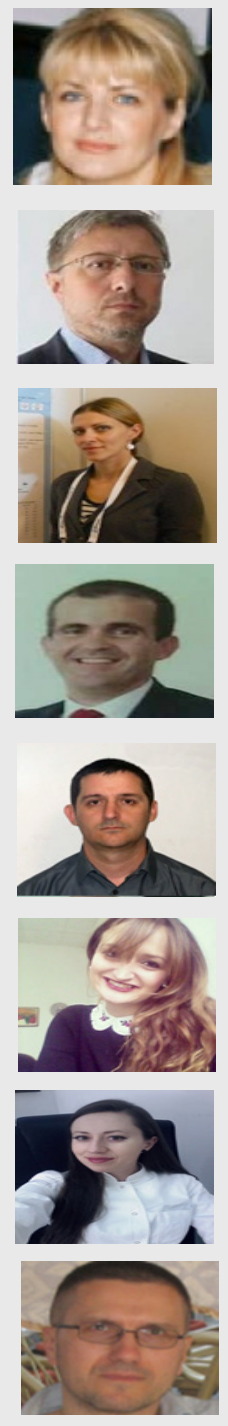

Milena Santric-Milicevic, is a Professor of Social Medicine at Medical Faculty and Center School of Public Health at the University of Belgrade at undergraduate and postgraduate level. Graduated at Medical Faculty, University of Belgrade, she latter defended MSc thesis and PhD. Specialist of Social Medicine.

Aleksandar Corac, is a of Preventive Medicine at Medical Faculty, University of Pristina, Kosovska Mitrovica, at undergraduate and postgraduate level. Graduated at Medical Faculty, University of Pristina. Specialist of Hygiene and Medical ecology.

Milica Paut Kusturica, is a of Department of Pharmacology, Toxicology and Clinical Pharmacology, Faculty of Medicine, University of Novi Sad, Novi Sad, Serbia.

Momcilo Mirkovic is Graduated at Medical Faculty, University of Pristina. Defended MSc thesis at Medical Faculty, University of Belgrade, and PhD thesis at the University of Pristina. Specialist of Social Medicine. He is working as aProfessor of Social Medicine, at the Medical Faculty, University of Pristina- Kosovska Mitrovica.

Zoran Bukumiric, is an assistant Professor of Medical statistics and informatics at Medical Faculty at the University of Belgrade at undergraduate and postgraduate level. Graduated at Medical Faculty, University of Pristina and defended his PhD thesis at the Medical Faculty, University of Belgrade. Specialist of Clinical Pharmacology and Medical Toxicology.

Jovana Todorovic, is graduated at Medical Faculty, Univeristy of Belgrade. Defended master degree in Physical activity, health and exercise therapy in 2016. Phd student. She is engaged in education of undergraduate and postgraduate students in the fields of Social Medicine, Public Health, and Health Management.

Biljana Ristic, is graduated at Medical Faculty and Faculty of Philology, University of Belgrade. Currently she is woking as a general practitioner.

Goran Trajkovic, is a professor of Medical statistics and informatics at Medical Faculty at the University of Belgrade at undergraduate and postgraduate level. Graduated at Medical Faculty, University of Pristina where he defended his PhD thesis. Specialist of Psychiatry.

Cite this article: Terzic-Supic Z, Bukumiric D, Santric-Milicevic M, Corac A, Kusturica MP, Mirkovic M, et al. Knowledge and Practices related to Unused Medications in Households in Serbia. Indian J of Pharmaceutical Education and Research. 2019;53(2):334-42. 